\title{
Differential expression of lipid metabolism genes in the liver and adipose tissue of mice treated with evodiamine
}

\author{
D.F. Jiang ${ }^{1,2}$, X.G. Zhang ${ }^{2}$, H.L. Yang ${ }^{1}$ and C. Sun ${ }^{1}$ \\ ${ }^{1}$ College of Animal Science and Technology, Northwest A\&F University, \\ Yangling, Shaanxi, China \\ ${ }^{2}$ Zhengzhou College of Animal Husbandry Engineering, Zhengzhou, \\ Henan, China \\ Corresponding author: C. Sun \\ E-mail: sunchao2775@163.com
}

Genet. Mol. Res. 12 (2): 1501-1510 (2013)

Received April 12, 2012

Accepted August 6, 2012

Published January 4, 2013

DOI http://dx.doi.org/10.4238/2013.January.4.13

\begin{abstract}
Evodiamine is the main active alkali of Wu Zhuyu, a widely distributed Chinese herb. It plays an important role in the regulation of body fat deposition. In this study, we aimed to investigate the effect of evodiamine administration on the expression of genes involved in lipid metabolism in the liver and adipose tissue. Fasted mice were subcutaneously injected with evodiamine $\left(37^{\circ} \mathrm{C}, 20 \mathrm{mg} / \mathrm{kg}\right)$, and the core body temperature change and expression levels of lipid metabolismrelated genes were evaluated at baseline, $0.5,1$, and $2 \mathrm{~h}$. We detected the mRNA expression of fatty acid synthesis enzyme (FAS), peroxisome proliferator-activated receptor gamma $(P P A R-\gamma)$, sterol regulatory element binding protein 1c (SREBP-1c), triglyceride hydrolase $(T G H)$, and hormone-sensitive lipase $(H S L)$ by real-time PCR and analyzed their correlation with core body temperature. Our results showed that the core body temperature was reduced greater than $1^{\circ} \mathrm{C}$ with evodiamine treatment at 1 and $2 \mathrm{~h}(\mathrm{P}<0.01)$. In mouse livers, SREBP-1c, HSL, and $T G H$ mRNA expression was significantly increased, and they reached the highest levels $1 \mathrm{~h}$ after injection $(\mathrm{P}<0.01)$. However, PPAR- $\gamma$ mRNA expression was decreased and reached a significant level at $0.5 \mathrm{~h}(\mathrm{P}<$
\end{abstract}


$0.01)$ and $F A S$ mRNA expression was not significantly different; $F A S$ and $S R E B P-1 c$ mRNA expression were reduced and reached significant levels at $1 \mathrm{~h}(\mathrm{P}<0.01)$. Of note, other genes demonstrated opposite changes in adipose tissue, and HSL mRNA expression was significantly reduced at $0.5 \mathrm{~h}(\mathrm{P}<0.01)$. The decreasing core temperature had a significant negative correlation with the expression of TGH, HSL, FAS, and SREBP$1 c$ mRNA in the liver $(\mathrm{P}<0.01)$, but had significant positive correlation with levels of FAS and SREBP-1c mRNA in adipose tissue $(\mathrm{P}<0.01)$. In light of these results, the main mechanism of the regulation of body fat deposition by evodiamine is raising energy consumption through reducing body temperature and promoting fat decomposition.

Key words: Evodiamine; Obesity; Lipid; Adipose tissue; Liver; Mice

\section{INTRODUCTION}

Obesity has become a worldwide personal and social health problem. Obesity can lead to abnormal metabolism of glucose and lipids in the human body, and cause diseases such as hypertension, type II diabetes and fatty liver. Recent studies also demonstrated that obesity could increase the risk of different types of cancer (Olsen et al., 2007; Mistry et al., 2007). Therefore, it is essential to discover new and effective treatment strategies to control this disease. In this respect, traditional Chinese medicine (TCM) holds the promise of developing new anti-obesity drugs, which might have fewer side effects than most of the therapeutic compounds currently being used in western countries. Among them, evodiamine is the main active alkali of the TCM plant Evodia rutaecarpa (Juss). It is well known for its anti-tumor, anti-inflammatory, and weight reduction effects. Moreover, it has been used for treatment of abdominal pain, diarrhea, and nausea and for producing many other pharmacological effects (Ogasawara et al., 2002; Shyu et al., 2006; Ko et al., 2007). More importantly, it is a natural compound and can be subject to a broad range of modifications and developments.

Previous studies have shown that evodiamine could induce the rate of lipolysis in mice and enhance the specific binding of guanosine diphosphate to mitochondria in interscapular brown adipose tissue, where it increased heat dissipation and promoted energy consumption. In addition, it also reduced perirenal, epididymal, and hepatic fat deposition, subsequently cut down the levels of free fatty acids, triglyceride (TG) and cholesterol in humans. All these effects were critical for preventing the accumulation of internal organ fat and controlling weight gain (Kobayashi et al., 2001). However, little is known regarding the mechanism by which evodiamine regulates the expression of genes involved in lipid metabolism pathways. Therefore, the purpose of the present study was to address the molecular mechanism mediated by evodiamine in controlling fat deposition.

\section{MATERIAL AND METHODS}

\section{Animal maintenance and treatment}

Male mice (20 $\pm 2 \mathrm{~g})$ were purchased from the Laboratory Animal Center of Fourth 
Military Medical University, and they were maintained in cages at $22^{\circ} \pm 2{ }^{\circ} \mathrm{C}$ with a 12 -h lightdark cycle. Each mouse was fed with a standard diet and allowed to drink water ad libitum. Evodiamine (purity $>98 \%$, Guanyu Biotechnology Inc., Xi'an, China) was dissolved in dimethyl sulfoxide (DMSO) according to manufacturer instructions. Forty-eight mice were randomly divided into 2 groups. After fasting for $12 \mathrm{~h}, 1$ group of animals received subcutaneous injections of evodiamine $(20 \mathrm{mg} / \mathrm{kg})$, whereas the other group received the same volume of DMSO solvent (vehicle) as a control. The injection mixture was pre-warmed to $37^{\circ} \mathrm{C}$ before use.

\section{RNA extraction and cDNA synthesis}

Total RNA was extracted from livers and adipose tissue using the Trizol reagent by standard techniques. The integrity of the RNA was checked on $2 \%$ agarose gels, and the total RNA concentrations were quantified by a spectrophotometer (Thermo, Waltham, MA, USA). Two micrograms total RNA was reverse-transcribed to synthesize cDNA using the PrimeScript RT-reagent Kit for real-time PCR (RT-PCR) after treatment with Dnase I to remove contaminating genomic DNA by the TRIpure Reagent Kit (Baitaike, Beijing, China) and diluted with diethylpyrocarbonate-treated water. The quality of the RNA samples was analyzed by electrophoresis on a $1 \%$ agarose gel. The first strands of cDNA were prepared with RevertAid ${ }^{\mathrm{TM}}$ First-Strand cDNA Synthesis Kit (Fermentas, Shenzhen City, China).

\section{RT-PCR}

Primers for fatty acid synthesis enzyme $(F A S)$, peroxisome proliferator-activated receptor gamma $(P P A R-\gamma)$, sterol regulatory element binding protein 1c (SREBP-1c), triglyceride hydrolase $(T G H)$, and hormone-sensitive lipase $(H S L)$ were designed by the Premier 5.0 software. Primer sequences and amplification conditions are given in Table 1. RT-PCR amplifications were carried out on a Bio-Rad iQ5 (Hercules, CA, USA) by SYBR Premix Ex Taq ${ }^{\mathrm{TM}}$ II chemistry detection under amplification conditions. The $2^{-\Delta \Delta \mathrm{Ct}}$ method was used for PCR data analysis. ${ }^{\Delta \Delta} \mathrm{Ct}=(\mathrm{Ct}$, target gene in the treated group - Ct, reference gene in the treated group) - (Ct, target gene in the control group - $\mathrm{Ct}$, reference gene in the control group).

\begin{tabular}{|c|c|c|c|}
\hline Gene & Primer sequences $\left(5^{\prime}-3^{\prime}\right)$ & Size (bp) & $\operatorname{Tm}\left({ }^{\circ} \mathrm{C}\right)$ \\
\hline$\beta$-actin & $\begin{array}{l}\text { F: ACTGCCGCATCCTCTTCCTC } \\
\text { R: CTCCTGCTTGCTGATCCACATC }\end{array}$ & 399 & 53.8 \\
\hline FAS & $\begin{array}{l}\text { F: AGTGTCCACCAACAAGCG } \\
\text { R: GATGCCGTCAGGTTTCAG }\end{array}$ & 280 & 55.9 \\
\hline$S R E B P-1 c$ & $\begin{array}{l}\text { F: CTGGAGACATCGCAAACAAGC } \\
\text { R: ATGGTAGACAACAGCCGCATC }\end{array}$ & 277 & 59.7 \\
\hline$P P A R \gamma$ & $\begin{array}{l}\text { F: ACCACTCGCATTCCTTTGAC } \\
\text { R: CCACAGACTCGGCACTCAAT }\end{array}$ & 261 & 52.1 \\
\hline$H S L$ & $\begin{array}{l}\text { F: GGAGCACTACAAACGCAAC } \\
\text { R: TCCCGTAGGTCATAGGAGAT }\end{array}$ & 357 & 57.9 \\
\hline$T G H$ & $\begin{array}{l}\text { F: CTTGGCTCCTTGAGATTTG } \\
\text { R: AGTTGGCAATGTTGTCCTG }\end{array}$ & 455 & 53.3 \\
\hline
\end{tabular}

$F A S=$ fatty acid syntesis; $S R E B P-1 c=$ sterol regulatory element binding protein; $P P A R \gamma=$ peroxisome profileratoractivated receptor gamma; $H S L=$ hormone-sensitive lipase; $T G H=$ triglyceride hydrolase. $\mathrm{Tm}=$ melting temperature. 


\section{Statistical analysis}

Statistical analysis was performed using the SPSS 13.0 program (SPSS, IBM Corporation, Endicott, NY, USA). One-way analysis of variance and the Fisher least significant difference test were applied to determine the significance of differences, and the Pearson correlation method was used in SPSS for correlation studies. Data are reported as means $\pm \mathrm{SE}$.

\section{RESULTS}

\section{Effect of evodiamine on core body temperature}

We first investigated the effect of evodiamine on core body temperature in mice. Mice were fasted for $12 \mathrm{~h}$, and then they were subcutaneously administered evodiamine (20 mg/ $\mathrm{kg}$ ) or DMSO only (vehicle) as a control. Core body temperature was measured at baseline, $0.5,1$ and $2 \mathrm{~h}$ after injection. Figure 1 shows the average core body temperature of mice after treatment with or without evodiamine. The core body temperature remained constant in the control group, whereas it dropped significantly in evodiamine-treated animals. The maximal difference was observed at $1 \mathrm{~h}$, when the core body temperature was approximately $1.5^{\circ} \mathrm{C}$ lower in evodiamine-treated animals than that of controls. This difference remained statistically significant $(\mathrm{P}<0.01)$ up to $2 \mathrm{~h}$. Since core body temperature is often associated with energy consumption in animals, the next step in our study was to detect the effect of evodiamine on the expression of various genes involved in lipid metabolism pathways.

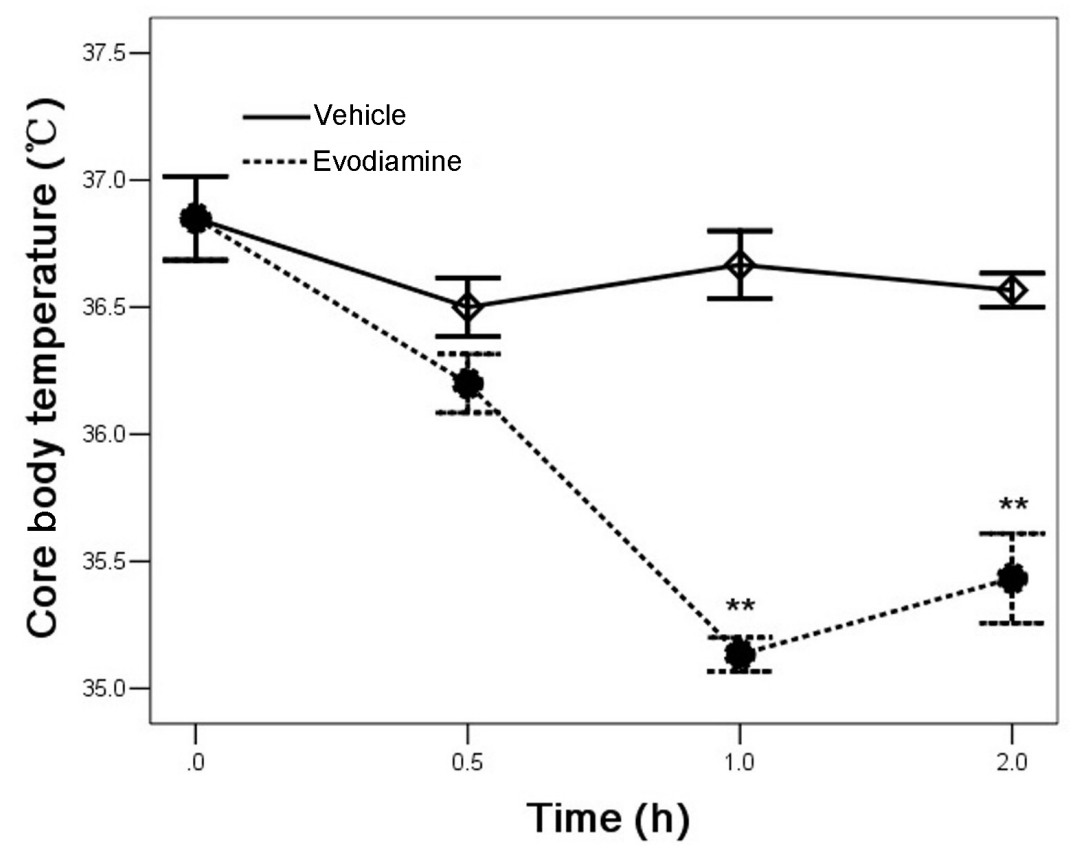

Figure 1. Effect of evodiamine on core body temperature in mice. Data are reported as the means \pm standard error for 6 mice. ${ }^{* *}$ Refers to significant difference at the level of $\mathrm{P}<0.01$. 


\section{The effect of evodiamine on FAS mRNA expression}

FAS expression is one of the limiting factors for fat deposition. Our results showed that evodiamine slightly enhanced the expression of FAS in mouse livers (Figure 2A); in contrast, it was drastically reduced in adipose tissue and reached significant suppression at $1 \mathrm{~h}$ after subcutaneous injection ( $\mathrm{P}<0.01$; Figure $2 \mathrm{~B})$. This result indicated that evodiamine could prevent visceral fat accumulation and weight gain, which might be related to the decreasing levels of FAS mRNA measured in the adipose tissue.
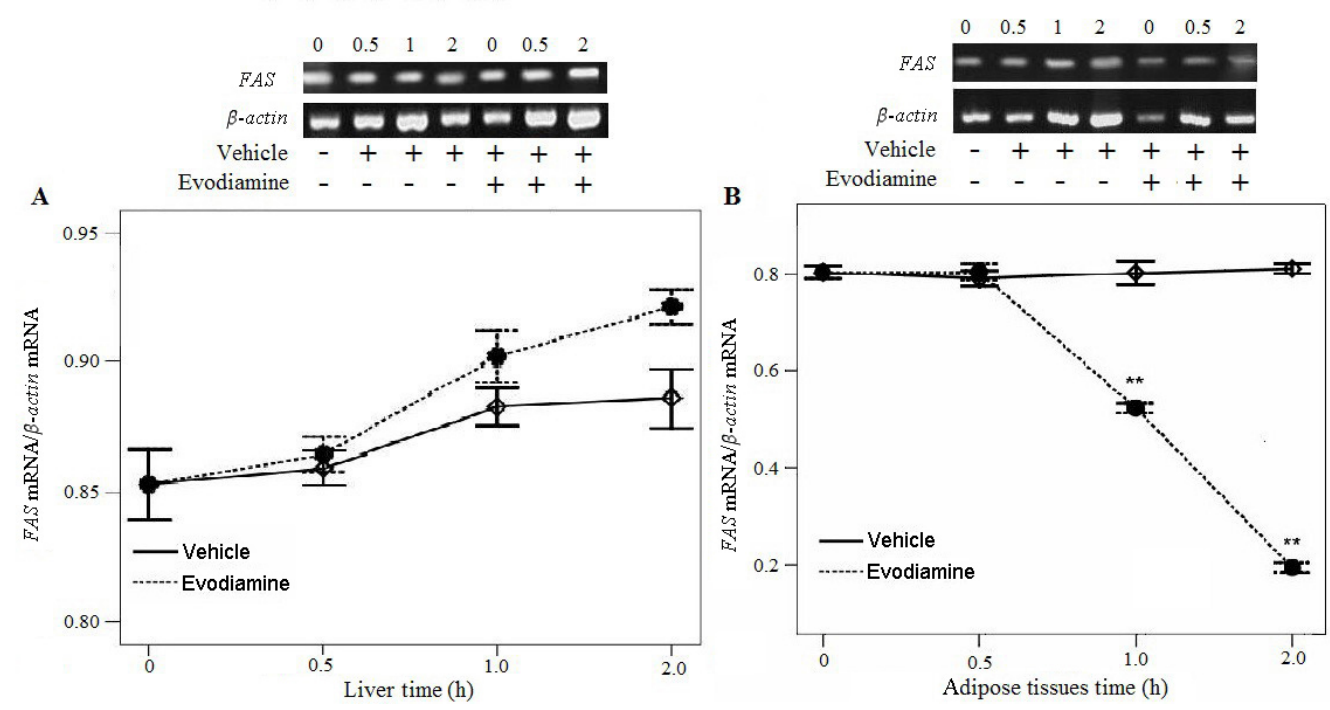

Figure 2. Evodiamine affected FAS mRNA expression in mouse liver (A) and adipose tissue (B). PCR products are revealed by agarose gel electrophoresis. Data are reported as means \pm standard error for 6 mice. ${ }^{* *}$ Refers to significant difference at the level of $\mathrm{P}<0.01$.

\section{Effect of evodiamine on PPAR- $\gamma$ and $S R E B P-1 c$ mRNA expression}

We investigated the effect of evodiamine on the expression of PPAR- $\gamma$ and SREBP-1c. The expression of $P P A R-\gamma$ mRNA in liver tissue was decreased after evodiamine treatment; it was significantly lower in the treated group than in the control group at $0.5 \mathrm{~h}(\mathrm{P}<0.01)$, and rebounded at $2 \mathrm{~h}$, with no significant difference between the groups (Figure $3 \mathrm{~A}$ ). While $P P A R-\gamma$ mRNA expression was increased in adipose tissue and reached a significant level at $1 \mathrm{~h}(\mathrm{P}<0.01)$, it was still significantly higher at $2 \mathrm{~h}$ in the treatment group $(\mathrm{P}<0.01)$ with little observed decline (Figure 3B). In mouse livers, evodiamine had no effect on SREBP-1c expression at $0.5 \mathrm{~h}$, but subsequently increased its level at 1 and $2 \mathrm{~h}$ (Figure 3C). In contrast, evodiamine reduced $S R E B P-1 c$ expression immediately following treatment in adipose tissue at $0.5 \mathrm{~h}$, and further decreases were observed, with the lowest level at $1 \mathrm{~h}$ (Figure 3D). SREBP$1 c$ expression had a slight increase at $2 \mathrm{~h}$, although the difference between evodiamine-treated and non-treated animals remained statistically significant $(\mathrm{P}<0.01)$. 


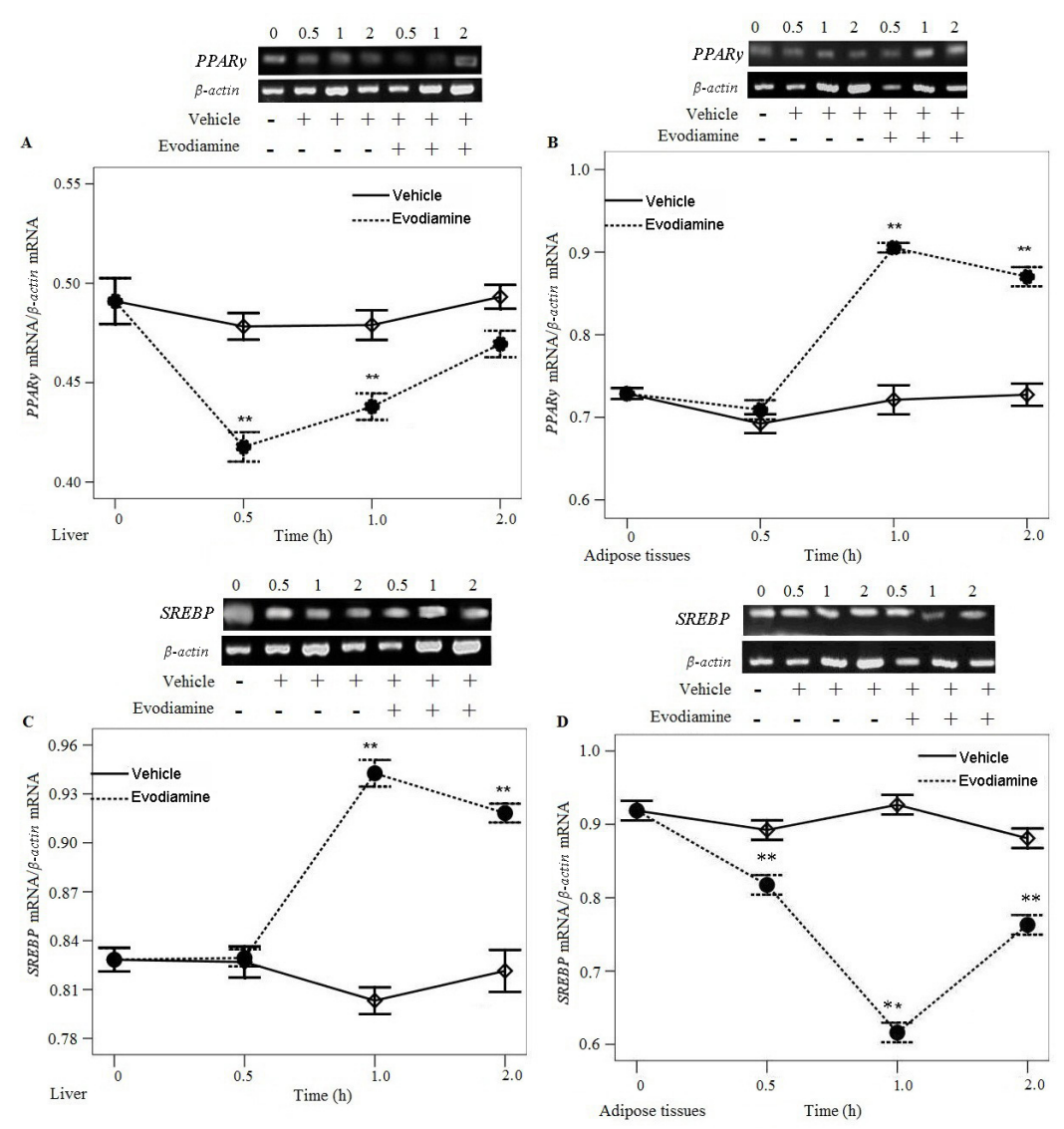

Figure 3. Effect of evodiamine on expression of lipogenesis regulating genes PPAR $(\mathbf{A}$ and $\mathbf{B})$ and $S R E B P-1 c$ $(\mathbf{C}$ and $\mathbf{D})$ in mouse liver (A and C) and adipose tissue (B and D). PCR products were revealed by agarose gel electrophoresis. Data are reported as means \pm standard error for 6 mice. **Refers to significant difference at the level of $\mathrm{P}<0.01$.

\section{Effect of evodiamine on the mRNA expression of lipolytic enzymes}

Given the results described above, we were interested in the effect of evodiamine on expression of genes involved in lipolysis. Our data showed that evodiamine had little effect on $T G H$ expression at $0.5 \mathrm{~h}$, but markedly increased $T G H$ levels were observed at $1 \mathrm{~h}$ in both mouse livers and adipose tissue (Figure 4A and B). TGH expression was further increased in livers at $2 \mathrm{~h}$ (Figure 4A), although these levels returned to baseline in mouse adipose tissue (Figure 4B). Compared to $T G H$ expression, similar effects of evodiamine on the expression of HSL were observed in mouse livers and adipose tissue (Figure 4C and D). The response of HSL expression to evodiamine treatment was rapid in adipose tissue, where it reached the maximal level at $0.5 \mathrm{~h}$ and then gradually descended, although the difference in expression was significantly different between the groups (Figure 4D). Taken together, evodiamine increased the levels of $T G H$ and HSL in both tissues, which suggested that evodiamine might exhibit a stronger and more direct effect on lipid metabolism. 


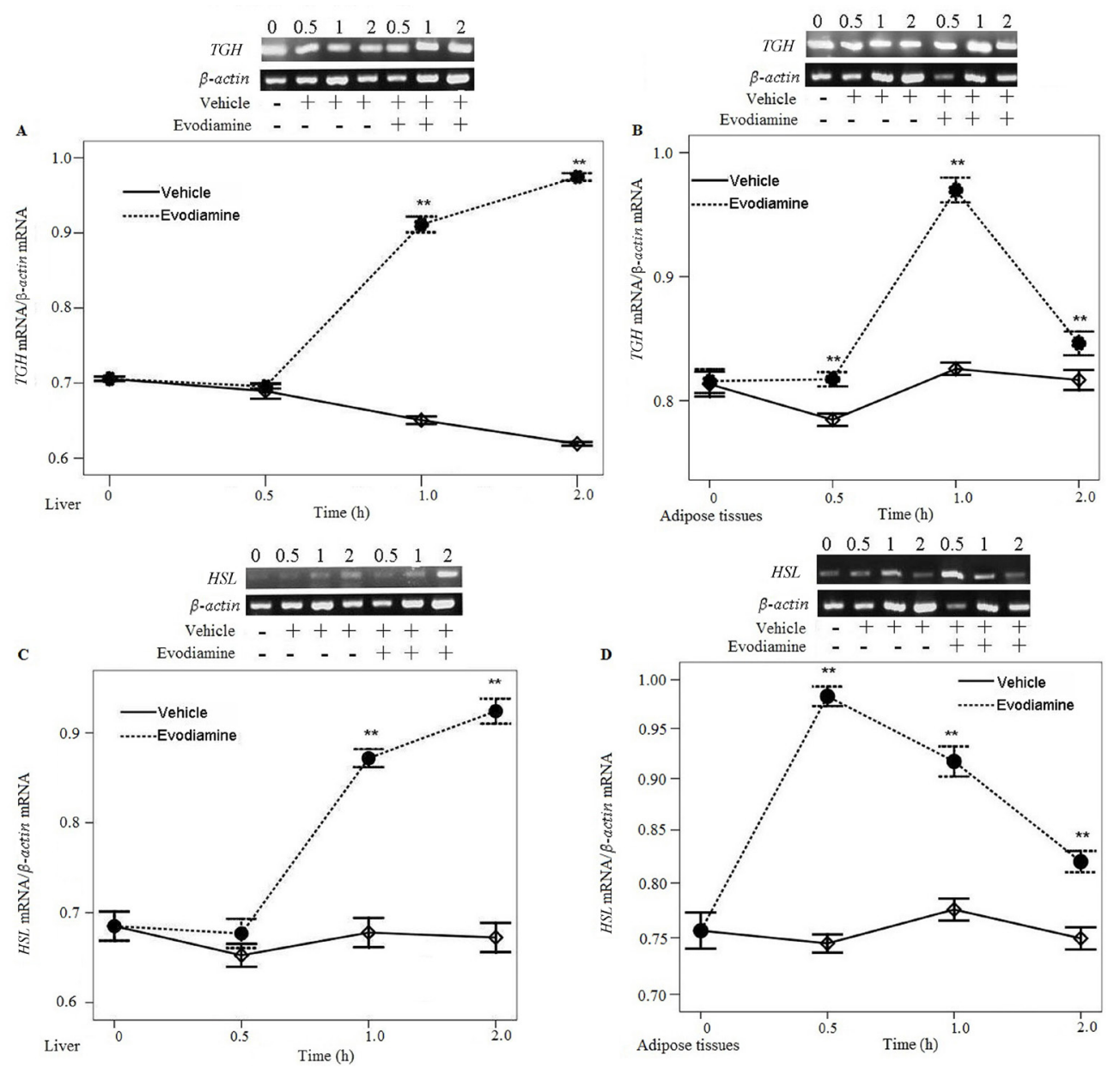

Figure 4. Effect of evodiamine on expression of lipolytic genes $T G H$ (A and $\mathbf{B})$ and $H S L(\mathbf{C}$ and $\mathbf{D})$ in mouse liver (A and C) and adipose tissue (B and D). PCR products were revealed by agarose gel electrophoresis. Data are reported as means \pm standard error for 6 mice. ${ }^{* *}$ Refers to significant difference at the level of $\mathrm{P}<0.01$.

\section{Correlation analysis of core body temperature and gene expression patterns}

To illustrate the overall effect of evodiamine on lipid metabolism, we performed a correlation analysis between core body temperature and expression of genes examined in the present study, which is summarized in Table 2 . This analysis revealed that decreased core body temperature was negatively correlated with the expression of $F A S$ and $S R E B P-1 c$ mRNA in the liver $(\mathrm{P}<0.01)$, while the opposite occurred in adipose tissue $(\mathrm{P}<0.01)$. With regard to $P P A R-\gamma$, a somewhat positive correlation was found in mouse liver, but it was not statistically significant $(\mathrm{P}>0.05)$; however, a strong negative correlation was found in adipose tissue. Interestingly, reduced core body temperature was negatively correlated with $T G H$ and $H S L$ expression $(\mathrm{P}<0.01)$ in both mouse livers and adipose tissue. 
Table 2. Correlation analysis of core body temperature with polyester gene expression.

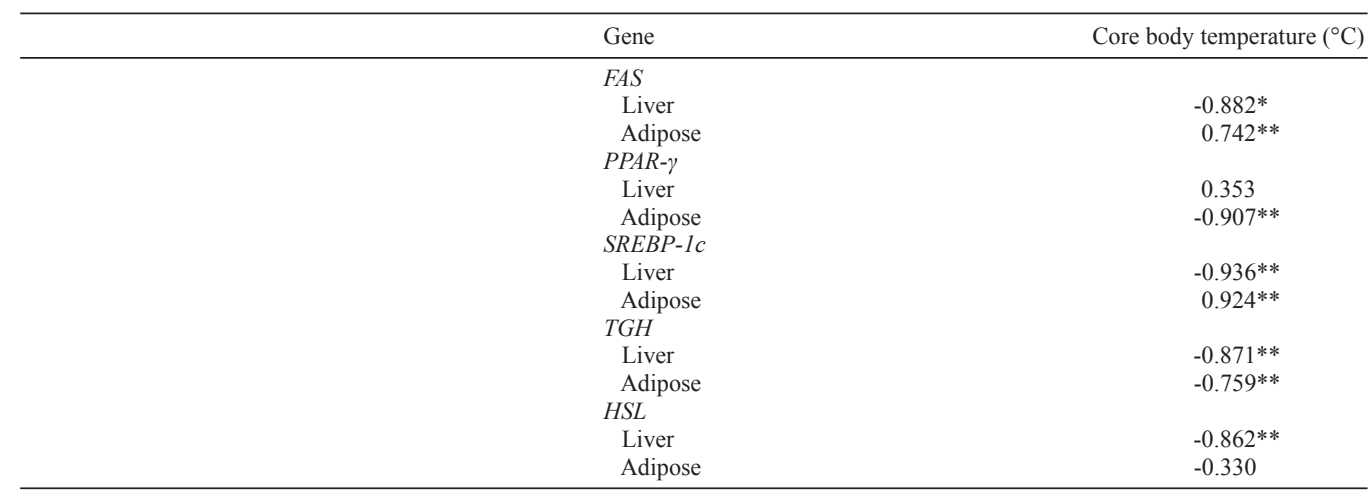

*Significant at 0.05 levels; **Significant at 0.01 levels (Pearson's correlation). For genes' abbreviations, see legend to Table 1.

\section{DISCUSSION}

Obesity is characterized by excessive body fat and is closely related to lipid metabolic disorders, in which the two reflect mutual causality. The lipid metabolic disorders could be caused by surfeit, resulting in increased fat synthesis and reduced brown fat content. In the present study, energy consumption was decreased and lipid-decreasing hormone expression was down-regulated, which induced fat synthesis and reduced its degradation. The theory of holistic medicine applied to a slimming diet through Chinese medicine meets 3 principles, which include weight loss without intense physical exercise, reduced appetite without anorexia and the absence of diarrhea (Feingold et al., 2008). Then, determining approaches for integrating TCM theories into modern biomedical technology has become an urgent need to be addressed.

In fat tissue, glucose and other nutrients are converted into fatty acids by the FASregulated pathway (Richards et al., 2003). Therefore, overexpression of $F A S$ would increase TG deposition in the body, which might cause obesity (Richards et al., 2003; Matsubara et al., 2005). Our results showed that expression of FAS was rapidly decreased upon evodiamine treatment in adipose tissue but not in the liver, indicating that this might be the main molecular mechanism by which evodiamine mediates its effects on weight loss. SREBP-1c is an important transcription factor that regulates the expression of FAS protein and lipoprotein lipase for fat synthesis (Kim and Spiegelman, 1996; Shimano et al., 1999). Therefore, we found that $S R E B P-1 c$ expression in adipose tissue was rapidly reduced by evodiamine, while in the liver, for unknown reasons, SREBP-1c expression was increased. PPAR- $\gamma$ plays multiple roles in glucose and lipid metabolism, atherosclerosis and inflammatory responses (Tontonoz et al., 1995; Li et al., 2000; Fernyhough et al., 2007; Széles et al., 2007; Rampino et al., 2007). It is involved in regulation of lipid metabolism-related genes, which promote the differentiation of adipocytes that secrete several protein factor genes, such as lipoprotein lipase, fatty acid binding protein, acetyl CoA synthetase, and glucose transporter 4. PPAR- $\gamma$ is a ligand-activating transcription factor, and upon activation it binds to retinoic acid $\mathrm{X}$ receptor to form a heterodimer, which acts on DNA response elements to regulate the gene expression of certain genes (Fajas et al., 1998; Yamauchi and Kadowaki, 2001). Specific ligands are involved in PPAR- $\gamma$ 
activation, which can be classified as synthetic and natural ligands; both types of ligands physically interact with the PPAR- $\gamma$ protein to participate in the process of fat synthesis. Due to these findings, PPAR- $\gamma$ had become a major molecular target for drugs used for treating obesity and diabetes. Other evidence had shown that Chinese medicine components, including the single-flavor drug, active ingredients and compound preparation, used for the treatment of obesity had effects on the expression of PPAR- $\gamma$ (Huang et al., 2006). Therefore, it was somewhat surprising that we found that evodiamine increased $P P A R-\gamma$ expression in adipose tissue (Figure 3A), while it decreased PPAR- $\gamma$ levels in the liver (Figure 3B). The reason for this finding might be 2 -fold. First, evodiamine could induce $P P A R-\gamma$ expression; second, the increase of PPAR- $\gamma$ could have been a secondary effect due to the accumulation of free fatty acids and lipid metabolites in evodiamine-treated animals. Nevertheless, the changes of PPAR- $\gamma$ and $S R E B P-1 c$ expression upon evodiamine treatment in adipose tissue and the liver were fairly rapid, indicating that they might be key players in fat synthesis and are very sensitive to the presence of evodiamine. The opposite effect of evodiamine on these 2 genes in adipose tissue and the liver might be due to a complex regulatory mechanism and differential biological effects of genes. Of note, the liver is the major site for energy consumption, whereas adipose tissue has the purpose of saving energy in mammals.

HSL and TGH are major intracellular hydrolysis enzymes in adipose tissue, which can catalyze TG to hydrolysis and produce free fatty acids, thus acting as an important energy source in vivo (Holm et al., 1988; Soni et al., 2004). The mRNA expression of HSL and TGH in the liver and adipose tissue was significantly increased after the treatment of evodiamine, and this effect was long lasting (data not shown). These findings suggested that TGH and HSL might be the direct targets of evodiamine and that the regulation of lipid metabolism by evodiamine could increase the expression of lipase mRNA.

Metabolic activities are accompanied by the release, metastasis and utilization of energy. In energy flow, 2 processes with opposite purposes are involved: catabolism is used to release energy, while anabolism is needed to the store energy. The latter is also called an "energy-absorbing reaction". In the present study, we found that evodiamine had a significant impact on the core body temperature of mice, consistent with the results of Kobayashi et al. (2001). Surprisingly, the decrease of body temperature by evodiamine exposure was associated with the increase of $T G H$ and HSL mRNA expression in both the liver and adipose tissues. In contrast, the increase in the $F A S$ and $S R E B P-1 c$ mRNA expression was only averted in the liver. Taken together, we concluded that the molecular mechanism by which evodiamine regulated body fat deposition was to reduce body temperature by simultaneously raising energy consumption and promoting fat decomposition.

\section{ACKNOWLEDGMENTS}

Research supported by the National Nature Science Foundation of China (\#31172185) and Science and the Technology Program of Shaanxi Province (\#2012NKC01-13).

\section{REFERENCES}

Fajas L, Fruchart JC and Auwerx J (1998). Transcriptional control of adipogenesis. Curr. Opin. Cell Biol. 10: 165-173. Feingold KR, Wang Y, Moser A, Shigenaga JK, et al. (2008). LPS decreases fatty acid oxidation and nuclear hormone receptors in the kidney. J. Lipid Res. 49: 2179-2187. 
Fernyhough ME, Okine E, Hausman G, Vierck JL, et al. (2007). PPAR $\gamma$ and GLUT-4 expression as developmental regulators/markers for preadipocyte differentiation into an adipocyte. Domest. Anim. Endocrinol. 33: 367-378.

Holm C, Kirchgessner TG, Svenson KL, Fredrikson G, et al. (1988). Hormone-sensitive lipase: sequence, expression, and chromosomal localization to 19 cent-q13.3. Science 241: 1503-1506.

Huang C, Zhang Y, Gong Z, Sheng X, et al. (2006). Berberine inhibits 3T3-L1 adipocyte differentiation through the PPAR $\gamma$ pathway. Biochem. Biophys. Res. Commun. 348: 571-578.

Kim JB and Spiegelman BM (1996). ADD1/SREBP1 promotes adipocyte differentiation and gene expression linked to fatty acid metabolism. Genes Dev. 10: 1096-1107.

Ko HC, Wang YH, Liou KT, Chen CM, et al. (2007). Anti-inflammatory effects and mechanisms of the ethanol extract of Evodia rutaecarpa and its bioactive components on neutrophils and microglial cells. Eur. J. Pharmacol. 555: 211-217.

Kobayashi Y, Nakano Y, Kizaki M, Hoshikuma K, et al. (2001). Capsaicin-like anti-obese activities of evodiamine from fruits of Evodia rutaecarpa, a vanilloid receptor agonist. Planta Med. 67: 628-633.

Li AC, Brown KK, Silvestre MJ, Willson TM, et al. (2000). Peroxisome proliferator-activated receptor gamma ligands inhibit development of atherosclerosis in LDL receptor-deficient mice. J. Clin. Invest. 106: 523-531.

Matsubara Y, Sato K, Ishii H and Akiba Y (2005). Changes in mRNA expression of regulatory factors involved in adipocyte differentiation during fatty acid induced adipogenesis in chicken. Comp. Biochem. Physiol. A Mol. Integr. Physiol. 141: 108-115.

Mistry T, Digby JE, Desai KM and Randeva HS (2007). Obesity and prostate cancer: a role for adipokines. Eur. Urol. 52: 46-53.

Ogasawara M, Matsunaga T, Takahashi S, Saiki I, et al. (2002). Anti-invasive and metastatic activities of evodiamine. Biol. Pharm. Bull. 25: 1491-1493.

Olsen CM, Green AC, Whiteman DC, Sadeghi S, et al. (2007). Obesity and the risk of epithelial ovarian cancer: a systematic review and meta-analysis. Eur. J. Cancer 43: 690-709.

Rampino T, Ranghino A, Guidetti C, Gregorini M, et al. (2007). Activation of PPAR $\gamma$ enhances in vitro the immunosuppressive effect of cyclosporine on T lymphocytes. Transpl. Immunol. 18: 32-36.

Richards MP, Poch SM, Coon CN, Rosebrough RW, et al. (2003). Feed restriction significantly alters lipogenic gene expression in broiler breeder chickens. $J$. Nutr. 133: 707-715.

Shimano H, Yahagi N, Amemiya-Kudo M, Hasty AH, et al. (1999). Sterol regulatory element-binding protein-1 as a key transcription factor for nutritional induction of lipogenic enzyme genes. J. Biol. Chem. 274: 35832-35839.

Shyu KG, Lin S, Lee CC, Chen E, et al. (2006). Evodiamine inhibits in vitro angiogenesis: Implication for antitumorgenicity. Life Sci. 78: 2234-2243.

Soni KG, Lehner R, Metalnikov P, O’Donnell P, et al. (2004). Carboxylesterase 3 (EC 3.1.1.1) is a major adipocyte lipase. J. Biol. Chem. 279: 40683-40689.

Széles L, Torocsik D and Nagy L (2007). PPAR $\gamma$ in immunity and inflammation: cell types and diseases. Biochim. Biophys. Acta 1771: 1014-1030.

Tontonoz P, Hu E and Spiegelman BM (1995). Regulation of adipocyte gene expression and differentiation by peroxisome proliferator activated receptor gamma. Curr. Opin. Genet. Dev. 5: 571-576.

Yamauchi T and Kadowaki T (2001). The molecular mechanisms by which PPAR $\gamma /$ RXR inhibitors improve insulin resistance. Nihon Rinsho 59: 2245-2254. 